\title{
A REVISTA HABITAT E A PROFISSIONALIZAÇÃO DO DESENHO INDUSTRIAL NO BRASIL NOS ANOS 1960
}

Patricia Amorim

ESPM-SP

pat.amorim@gmail.com

Virginia Pereira Cavalcanti

Universidade Federal de Pernambuco

cavalcanti.virginia@gmail.com

Resumo: Este artigo caracteriza brevemente o projeto editorial e gráfico da revista cultural paulistana Habitat, fundada em 1950, com foco no tema da profissionalização do desenho industrial no país. A partir de uma abordagem histórica, foram coletados e analisados textos publicados por Habitat entre 1950 e 1965, com o intuito de identificar os principais aspectos relacionados à fase inicial de institucionalização acadêmica e classista do desenho industrial no Brasil. Nesse conjunto, destacam-se questões como a definição da profissão e seu papel social; os enfoques pedagógicos necessários à formação desse profissional; e desafios no contexto da indústria nacional, como a cópia ou a compra de projetos importados.

Palavras-chave: Desenho industrial, revista, Habitat.

Abstract: This paper briefly characterizes the editorial and graphic approach of cultural magazine Habitat, founded in São Paulo, in 1950, focused on the professionalization of industrial design in Brazil. From a historical perspective, articles published by Habitat between 1950 and 1965 were collected and analyzed, in order to identify the main aspects related to the early stage of academic and professional institutionalization of industrial design in the country. We highlight issues such as the definition of the profession and its social role; pedagogical approaches needed for the designer's academic background; and challenges faced by the national industry, such as plagiarism or royalty payment for imported design projects.

Keywords: Industrial design, magazine, Habitat. 


\section{INTRODUÇÃO}

No Brasil - e principalmente em cidades como São Paulo e Rio de Janeiro revistas ligadas à arquitetura e às artes repercutiram e debateram a emergência e institucionalização de desenho industrial no país, constituindo um valioso repertório de fontes sobre esse fenômeno em meados do século XX. Habitat foi uma delas. A publicação nasceu em 1950 (fig.1), na cidade de São Paulo, fundada pela arquiteta Lina Bo Bardi e seu marido, o jornalista e crítico de arte Pietro Maria Bardi, ambos de origem italiana, então líderes intelectuais do imberbe Museu de Arte de São Paulo (MASP). A revista fez parte do projeto de modernização cultural implementado pelo casal no país, o qual tinha o museu e as escolas ali criadas como núcleo, dentre elas o Instituto de Arte Contemporânea (IAC), onde funcionou o pioneiro curso de desenho industrial de orientação moderna no Brasil.

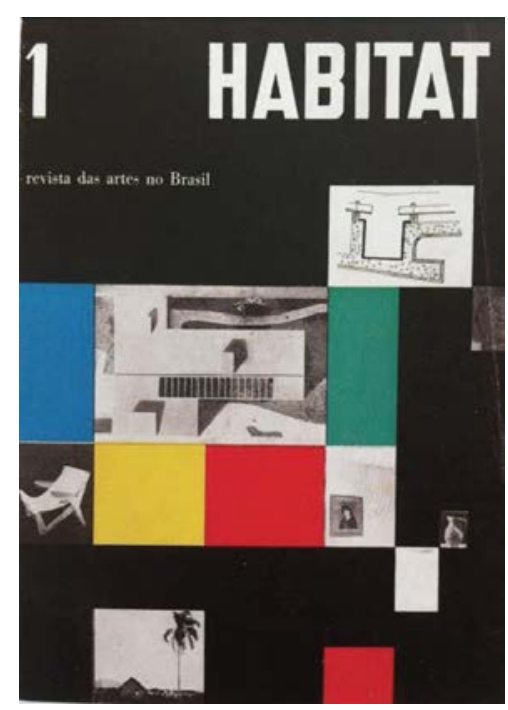

Figura 1 - Capa da revista Habitat, № 1. Acervo: Biblioteca FAU/USP. Reprodução: P. Amorim.

Tendo em vista tal cenário, este artigo faz uma breve caracterização do projeto editorial e gráfico dessa publicação, com foco no tema da profissionalização do desenho industrial no país na década de 1960. A partir de uma abordagem histórica, foram coletados e examinados, segundo a técnica da análise de conteúdo (FRANCO, 2005), textos publicados por Habitat entre 1950 e 1965, com o intuito de identificar os principais aspectos relacionados à fase inicial de institucionalização acadêmica e classista do desenho industrial no Brasil.

\section{O SENTIDO DE HABITAT}

De acordo com Stuchi (2007), correspondências entre Lina Bo Bardi e Sigfried Gideon, então secretário-geral do Congresso Internacional de Arquitetura Moderna (CIAM), no final da década de 1940, mostram que o projeto inicial da revista Habitat previa o engajamento do arquiteto Oscar Niemeyer, de Eduardo Kneese de Mello, diretor do Instituto dos Arquitetos do Brasil (IAB), do pintor Candido Portinari, da própria Lina e também de seu colega e conterrâneo, o arquiteto Giancarlo Palanti, o qual vivia no Brasil desde 1946 (STUCHI, 2007). 
Ao ser lançada em 1950, apenas Palanti se confirmaria como um dos colaboradores da publicação, ao lado de Lina e Pietro Maria Bardi, levando-se em consideração o grupo reunido na fase embrionária do projeto da revista.

Com amplo interesse na produção das mais diversas áreas da cultura no Brasil, Habitat se propunha a divulgar e debater a arquitetura, as artes plásticas, a fotografia, o cinema, a música, o desenho industrial e a publicidade. Segundo Stuchi, Habitat atuaria também "como meio de ampliar os limites e alterar o gosto estabelecido, ultrapassando as fronteiras culturais da classe dirigente" (STUCHI, 2007:14). Seu discurso de modernidade, baseado nos valores, expectativas e também nas frustrações vividas desde as experiências pregressas de Lina e P. M. Bardi na Itália, encontraria na arquitetura seu principal veículo. E isso fica claro no trecho do editorial do primeiro número da revista:

("Habitat" significa ambiente, dignidade, conveniência, moralidade de vida, e portanto espiritualidade e cultura: é por isso que escolhemos para título desta nossa revista uma palavra intimamente ligada à arquitetura, à qual damos um valor e uma interpretação não apenas artística, mas uma função artisticamente social.). HABITAT, n.1, 1950, p. 1.

A redação de Habitat, assim como o MASP naquele período, funcionou no prédio dos Diários Associados durante a maior parte de sua existência ${ }^{1}$. Circulou por 14 anos e teve 84 números publicados, entre outubro de 1950 e julho 1965, encerrando suas atividades logo após a instalação do regime militar no país. Ao longo desse período, a liderança do corpo editorial - que reuniu arquitetos, artistas e jornalistas entre seu variado grupo de colaboradores, geralmente integrantes do círculo de amizades do casal Bardi - poucas vezes se alterou.

Do primeiro ao nono número, entre outubro de 1950 e dezembro de 1952, a revista contou com a direção geral de Lina Bo Bardi. Nas edições 10 a 13, entre janeiro e outubro de 1953, Flávio Motta, ex-diretor do Jornal Artes Plásticas, assistente de Bardi no museu e professor do Instituto de Arte Contemporânea, assumiu temporariamente a posição, ele que era uma dos principais colaboradores da revista. Nos números 14 e 15, durante o primeiro semestre de 1954, Lina retornou, compartilhando o cargo com seu marido.

Logo em seguida, o casal afastou-se definitivamente do comando da equipe editorial de Habitat, alegando demandas urgentes do MASP².

O momento da saída dos fundadores da publicação coincide também com a conclusão de sua etapa inaugural. Período no qual foi talhado o caráter de Habitat e quando foram postos em evidência temas considerados prioritários no campo da arte

\footnotetext{
${ }^{1}$ A partir da edição 66, de 1961, a redação, administração e publicidade da revista passou a funcionar no endereço da gráfica Habitat Editora, na rua dos Lavapés, 540, São Paulo.

2 Em função do questionamento da autenticidade das obras do museu por parte de alguns órgãos de imprensa locais, em 1953 a coleção do MASP foi enviada à França para verificação. Após certificação de legitimidade, peças do acervo foram exibidas no Musée de L'Orangerie, em Paris, e depois em outros museus na Europa e nos Estados Unidos, numa turnê que seguiu até 1957. Em entrevista a Fabiana Stuchi (2007), Luiz Hossaka, ex-aluno do IAC e secretário de Bardi no MASP, apresentou, em sua opinião, outros dois motivos que teriam levado o casal a afastar-se da revista: a imposição de um novo projeto gráfico por parte do editor Rodolfo Klein e o forte caráter crítico da publicação, que nem sempre era bem aceito socialmente.
} 
e da arquitetura no Brasil naquele momento. Vale ressaltar que, a partir da edição 46, publicada em janeiro de 1958, Bardi retornaria como colaborador esporádico.

Na edição 17, o cargo de diretor geral é extinto e Habitat passa a funcionar sob o gerenciamento de diretores de seção. O arquiteto carioca Abelardo de Souza, veterano colaborador da revista, professor na Faculdade de Arquitetura e Urbanismo da Universidade de São Paulo (FAU USP) e sócio de um escritório em São Paulo com os arquitetos Hélio Duarte e Zenon Lotufo, ficou à frente da direção de arquitetura durante as edições 16 a 24, ou seja, entre maio de 1954 e outubro de 1955. A direção de artes plásticas foi confiada a José Geraldo Vieira desde a edição 16 e, entre os números 19 e 21, Ruggero Jacobbi chefiou a direção de teatro e Maria de Lourdes Teixeira, a de literatura.

A partir da edição 25, lançada em dezembro de 1955, até o fechamento da revista, dez anos depois, a direção de arquitetura - a qual o tema do desenho industrial estava vinculado - foi ocupada pelo escritor, jornalista e crítico de arte Geraldo Ferraz. Integrante do movimento modernista brasileiro, Ferraz havia sido secretário da Revista de Antropofagia e fundador dos periódicos Correio da Tarde e Vanguarda Socialista.

Ainda nessa ocasião, ao ser publicado seu $25^{\circ}$ número ${ }^{3}$, Habitat comemorou seis anos de existência, passando a circular mensalmente. Em seu editorial, um "novo" programa de trabalho era apresentado, com foco na arquitetura, no urbanismo e nas artes, além de demonstrar um claro entusiasmo com a perspectiva de uma etapa de desenvolvimento e industrialização no país, aventada com a chegada de Juscelino Kubitscheck à Presidência da República naquele mesmo ano.

Inspira-nos a certeza de que, desta maneira, estaremos dando novo impulso e maior objetividade à aspiração do equipamento urbano, atenta à dinâmica de um progresso que já deixa de ser adstrito ao plano da subsistência, para alçar-se a uma industrialização habilitada a dispensar importações onerosas de instrumentos de trabalho, proporcionando-nos breve, a possibilidade de um surto de autossuficiência, o grande espaço econômico, do sul do nosso hemisfério. HABITAT, n.25, 1955, p. 1.

Na edição 57, ao completar dez anos em circulação, a revista confirmava sua busca, apesar dos inúmeros desafios, em espelhar a vitalidade dos que trabalham e se sentem inspirados pela arte brasileira":

Se o papel de pioneiros ainda deve ser evocado, inauguramos a segunda parte do século XX no Brasil com uma publicação que não possuía público, acústica e compreensão. Hoje, essas condicionantes já se fazem sentir; entretanto dificuldades econômicas e financeiras, no processo de crescimento do país, apresentaram-se com um cortejo de obstáculos, aos quais nos sobrepomos sempre, cuidando do futuro que emerge destas semeaduras. HABITAT, n.25,

\footnotetext{
${ }^{3}$ Também a partir do número 25 , os cargos de diretor responsável e redator-chefe de Habitat foram acumulados por Geraldo Serra. De acordo com Stuchi (2007), entretanto, Serra aparecia no expediente como diretor responsável já que Rodolfo Klein, proprietário da Habitat Editora e agora redator da revista, era impossibilitado pela legislação brasileira de assumir a posição oficialmente por ser estrangeiro.
} 
1955, p. 1

Publicada em julho de 1965, a última edição de Habitat [fig.48], entretanto, se mostraria abatida pelas dificuldades e obstáculos que continuaram a se impor. Se no cenário político Brasília e o país sucumbiam ao regime militar, no campo da arquitetura e do desenho industrial as notícias não eram melhores. Na capa, a revista anunciava a saída de cena de grandes mestres: De luto a arquitetura mundial: desaparecem Rino Levi e Le Corbusier. E em seu último editorial, lia-se: Falta de perspectiva profissional, em referência à insatisfação de alunos da FAU USP diante das limitadas oportunidades para o desenvolvimento da carreira. Lamentava-se a reduzida participação de arquitetos na construção de prédios na cidade, a ausência de um plano piloto urbanístico em São Paulo e a não regulamentação da profissão. "No Plano Nacional de Habitação, o concurso de arquitetos que deveria ser o máximo possível, foi irrisório e no campo da produção industrial, no Brasil que é o maior produtor de café, não existe cafeteira com desenho nacional" (HABITAT, n. 84, 1965, p. 14), observava o periódico.

A área do desenho industrial, problematizada, nesse caso, a partir de uma crise no mercado de trabalho dos arquitetos, lidava com entraves como a compra de projetos concebidos no exterior: "a indústria também não os utiliza [os arquitetos] na racionalização da produção ou na melhora da aparência dos seus produtos e prefere pagar 'royalties' a desenhos vindos de outras partes" (Ibidem, p.14).

A revista despedia-se. Era evidente seu raquitismo editorial (matérias em tom burocrático), gráfico (formato reduzido e diagramação engessada) e comercial (uso de calhaus da Gráfica Habitat e reduzida quantidade de anúncios pagos) se comparada ao vigor dos primeiros anos. O ciclo de Habitat havia se consumado, ficando ainda irrealizadas muitas das expectativas que, 14 anos atrás, haviam alimentado seu surgimento.

\section{A FORMA GRÁFICA DE HABITAT}

A publicação teve periodicidade variada, alternando temporadas de circulação trimestral, bimestral e mensal. Sua distribuição também oscilou ao longo dos anos, embora mantivesse representação no Rio de Janeiro e, eventualmente, em outros pontos do país, como Salvador, Porto Alegre, Recife e Belo Horizonte, o que ampliava seu alcance a outras regiões. No exterior, Habitat contou com representantes na Argentina, no Uruguai, em Portugal e nos Estados Unidos. Em atenção ao público leitor internacional, a revista publicou, mesmo com frequência irregular, resumos em inglês de suas principais matérias.

O aspecto gráfico de Habitat é um tema rico e complexo, merecedor de estudos específicos, mas que ultrapassa os limites deste trabalho. De modo geral, entretanto, pode-se afirmar que a revista adotou, até o início da década de 1960, recursos típicos do layout modernista, como páginas arejadas por generosas áreas em branco, a valorização da fotografia, muitas vezes utilizada em grandes formatos e o uso da fonte tipográfica Futura. Embora a autoria do projeto gráfico não conste no expediente da revista, é visível, na fase inicial, a influência estética de Domus, uma das publicações para as quais Lina Bo Bardi colaborou ainda na Itália.

Suas dimensões originais, $23 \mathrm{~cm} \times 31,5 \mathrm{~cm}$ (formato fechado), foram reduzidas em junho de 1963, na edição 72 , passando para $21 \mathrm{~cm} \times 28,5 \mathrm{~cm}$, ocorrendo aí também 
reformulação na diagramação interna. O miolo era impresso em preto e branco, salvo raras exceções - inicialmente usava-se o papel couché, substituído em seguida por papel offset e, nas últimas edições, o papel jornal. A capa era composta, geralmente, a partir de um fundo colorido de cor chapada, sobre o qual eram aplicadas fotos de pinturas, esculturas ou ilustrações. Outra característica gráfica da revista era o uso de papéis especiais no expediente, nos resumos em inglês e na demarcação de conteúdo específico, como em aberturas da seções [fig.2], por exemplo.

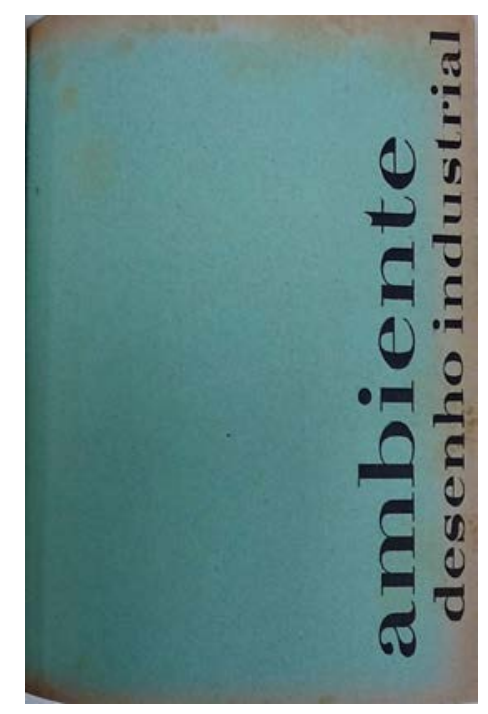

Figura 2 - Abertura da seção Ambiente desenho industrial. Habitat $\mathbf{N}^{\circ}$ 79. Fonte: Biblioteca FAU/USP. Reprodução: P. Amorim.

Batizada "Habitat - Revista das artes no Brasil", seu subtítulo seria ajustado periodicamente, sinalizando aos leitores afinações ocorridas na abordagem editorial da publicação, em decorrência da seleção de novos temas em destaque.

No caso específico do termo "desenho industrial", este seria incorporado ao subtítulo de Habitat em duas épocas distintas. A primeira, ao longo das edições 14 a 24, onde lia-se, no topo da página do editorial, "Revista de cultura contemporânea, dedicada à arquitetura, pintura, escultura, desenho industrial e artes visuais". Foi assim entre janeiro de 1954 e dezembro de 1955, período marcado pela despedida do casal Bardi da direção da revista e pela gerência de Abelardo de Souza na seção de arquitetura. Esse foi também o momento posterior ao encerramento das atividades do IAC, fato que, pelo visto, não desencorajou a inclusão do termo desenho industrial à descrição da publicação, embora, curiosamente, nesse mesmo período, a publicação de matérias relativas ao tema tenha sido inexistente.

Dez anos depois, entre março de 1964 e julho de 1965, nas edições 76 a 84, ciclo final de Habitat, o subtítulo da publicação diria, também na página do editorial, "Revista brasileira de arquitetura, artes plásticas, decoração interna, paisagismo, ambiente, mosaico e desenho industrial". Nessa época, meados da década de 1960, o campo do desenho industrial no país já se apresentava mais organizado e articulado, através de iniciativas de natureza educacional e profissional. Assim, pode-se compreender a incorporação do termo ao subtítulo de Habitat, nesse período, também como reflexo desse novo momento da atividade no Brasil. 


\section{O DESENHO INDUSTRIAL NO BRASIL NO INÍCIO DA DÉCADA DE 1960}

Em 1958, a profissionalização do desenho industrial no país ganhou reforço com a fundação do fominform, em São Paulo. O primeiro escritório de desenho industrial "sem a presença de arquitetos" reunia os artistas plásticos Geraldo de Barros e Ruben Martins, ambos também com experiência em desenho de mobiliário, o publicitário e administrador Walter Macedo, e Alexandre Wollner, recém-chegado de sua graduação na HfG-Ulm. Nesse mesmo período, outros escritórios também nasceriam na cidade, de acordo com o próprio Wollner:

No final da década de 50, começaram a surgir em São Paulo alguns escritórios de design com a intenção de seguir o modelo do forminform: Maurício Nogueira Lima inaugurou um escritório onde atendia especialmente as feiras industriais de Caio de Alcântara Machado; João Carlos Cauduro, depois de um estágio na Itália e outro com Ruben Martins no forminform (após minha saída), abriu seu escritório associado a Ludovico Martino; Willys de Castro, pintor concreto independente (que não pertenceu ao movimento Ruptura), autodidata em comunicação visual, criou alguns signos principalmente para galerias de arte e embalagens para tintas Cil. Vale lembrar ainda a importância do pintor português radicado no Brasil Fernando Lemos, que nessa época começava a atuar também como designer. Maurício, Ludovico e eu havíamos sido colegas no IAC; no entanto, deve-se salientar o quanto era difícil seguir aquele modelo, pois o enfoque do forminform era estruturado programaticamente em projetos mais consistentes do que a produção de signos isolados. (WOLLNER, 2003:131)

Já no Rio de Janeiro, em 1960, surge o MNP (Magalhães + Noronha + Pontual), o qual se tornaria um dos mais importantes escritórios de programação visual do país, reunindo inicialmente o artista plástico Aloisio Magalhães, o arquiteto Artur Lício Pontual e o administrador Luis Fernando Noronha. Com a desvinculação de seus dois sócios em 1963, Aloisio passa a liderar o escritório sozinho, rebatizando-o de AMPVDI (Aloisio Magalhães Programação Visual Desenho Industrial), em 1966 (LEITE, 2003). Embora rejeitasse a transplantação de ideias importadas, Aloisio reconhecia o léxico construtivo e os métodos da HfG-Ulm, buscando utilizá-los em seus projetos de identidade visual em adequação à realidade industrial local (STOLARSKI, 2008).

O início da década de 1960, entretanto, também seria marcado pela institucionalização da atividade no âmbito do ensino e da representação de classe. Em 1962, o curso de arquitetura da FAU USP inclui uma sequência de disciplinas de desenho industrial em sua matriz curricular, em decorrência de uma reforma liderada pelo arquiteto e professor Vilanova Artigas. No ano seguinte, no Rio de Janeiro, a Escola Superior de Desenho Industrial (ESDI), buscando adotar uma filosofia semelhante à da HfG-Ulm, entra em funcionamento, sendo ali inaugurado o primeiro curso inteiramente dedicado à área, em nível superior, no Brasil. Também em 1963, é criada, em São Paulo, a Associação Brasileira de Desenho Industrial (ABDI), com o objetivo de difundir a atividade nacionalmente e promover a interação entre os profissionais da área.

Em 1964, três artigos sintomáticos desse novo momento da atividade no país seriam publicados em Habitat. Seus autores, os arquitetos João Carlos Cauduro e Lúcio Grinover e o poeta concretista Décio Pignatari, estavam entre os protagonistas desta cena. Cauduro e Grinover eram professores da FAU USP de disciplinas da sequência de 
desenho industrial. Além disso, os três fizeram parte do grupo de fundadores da ABDI, sendo que Grinover foi nomeado o primeiro presidente da instituição e Pignatari, 0 diretor de informação. Este, por sua vez, também integraria o corpo docente da ESDI.

Tendo em vista a necessidade de conscientizar o empresariado sobre o desenho industrial e assim estimular sua ampliação no mercado de trabalho, a ABDI articulou várias iniciativas de divulgação. De acordo com Braga (2011), promoveu palestras; apoiou exposições e concursos, como o Prêmio Roberto Simonsen; organizou, em 1964, o I Seminário de Ensino de Desenho Industrial, em conjunto com a FAU USP, a ESDI e a Federação das Indústrias do Estado de São Paulo (FIESP). Publicou, neste mesmo ano, também com a FIESP, o livro Desenho industrial: aspectos sociais, históricos, culturais e econômicos, resultado de um evento de divulgação da profissão para empresários com apoio do Fórum Roberto Simonsen; e criou a revista Produto e Linguagem (DIAS \& BRAGA, 2012), que teve três números lançados entre 1965 e 1966, e outras duas edições especiais em 1977.

Habitat, por sua vez, cedeu espaço de suas páginas a ABDI, ao veicular artigos assinados por Cauduro, Grinover e Pignatari, nas edições 76 e 77. Segundo Braga, tais textos também foram publicados no livro e na revista acima mencionados e baseavamse nas conferências por eles proferidas. ${ }^{4}$

Em Origem e desenvolvimento do desenho industrial no Brasil, Cauduro esboça uma revisão histórica da atividade no país, para assim contextualizar o surgimento da ABDI. Estabelece como marco inicial a reformulação das relações da cultura com a indústria, empreendida, nos anos 1930, por arquitetos comandados por Lúcio Costa, no Rio de Janeiro. Menciona ainda pioneiros como Warchavchik, Flávio de Carvalho, Rino Levi e Vilanova Artigas. Dos anos 1940, cita experiências no âmbito do desenhos de móveis em madeira recortada e compensada, realizadas por Zanine Caldas e pelo Studio de Arte Palma; e no campo gráfico, a atuação da sucursal da agência de publicidade Raymond Loewy Associates, que criou marcas para as indústrias Pignatari, utensílios de alumínio para a Rochedo e a linha de móveis Brafor. No âmbito do ensino, faz referência ao MASP e ao IAC, e observa que no final da década de 1950, "alguns escritórios e alguns profissionais liberais surgem no mercado, em São Paulo e no Rio de Janeiro, já com uma nova consciência da profissão de desenhista industrial" (CAUDURO, 1964: 50).

Dentre as realizações mais recentes, Cauduro cita as experiências de ensino na FAU USP e na ESDI; a participação do Brasil, em junho de 1963, no III Congresso Internacional de Desenho Industrial, em Paris, promovido pelo International Council of Societies of Industrial Design (ICSID); e por fim, a fundação da ABDI, em agosto de $1963^{5}$. Deste modo, estava apresentada uma espécie de árvore genealógica dessa entidade de classe, cujos cinco objetivos também foram ali expostos. Em síntese: congregar os profissionais da área, favorecer o desenvolvimento e a qualificação da profissão, divulgar as atividades dos sócios, assessorá-los juridicamente e trabalhar no

\footnotetext{
${ }^{4}$ Segundo Braga, em depoimento a este trabalho, "como na época eram raros os textos em português sobre o design, o esforço dessas palestras gerou uma quantidade considerável de textos que serviu durante um tempo como referências conceituais para eles na abdi e para os empresários com quem tinham contato".

${ }^{5}$ Neste artigo publicado em Habitat, Cauduro informa que a fundação da abdi ocorreu em agosto de 1963. De acordo com Braga (2011), a primeira ata de reunião da entidade tem data de 10 de setembro de 1963.
} 
sentido do reconhecimento e regulamentação da profissão. Em sua conclusão, Cauduro acenava para o futuro: "O que foi realizado até agora no desenho industrial, constitui em verdade, a base que nos dá condições para doravante empreendermos aquelas tarefas que a sociedade brasileira, através de sua realidade industrial, espera de nós" (Ibidem, p.50).

Nesta mesma edição de Habitat, de março/abril de 1964, também foi publicado o artigo Desenho industrial, assinado por Lúcio Grinover. Docente da disciplina de desenho industrial da FAU USP e presidente da ABDI (de 1963 a 1968), Grinover foi também o primeiro no Brasil a defender uma tese de livre docência tendo o desenho industrial com o tema: As implicações da ciência e do pensamento lógico no desenho industrial (BRAGA, 2011). No texto publicado em Habitat, numa linha distinta porém complementar a de Cauduro, Grinover enfatizou o papel do desenho industrial na sociedade e expôs uma definição da atividade:

O termo "Desenho Industrial", tradução do inglês "Industrial Design" traz consigo uma grande série de equívocos, que devemos eliminar da maneira a mais definitiva e absoluta. Desenho Industrial não é desenho técnico. Desenho Industrial não é decoração. Desenho Industrial não é embelezamento do produto. Desenho Industrial não é "Arte Aplicada". Desenho Industrial é o planejamento Técnico-Formal do produto; isto é, o projeto de objetos destinados à produção em série, visando a qualidade dos mesmos, dentro das necessidades sociais, econômicas e culturais ditadas pela época e pela comunidade para a qual ele atua. (GRINOVER, 1964: 52).

Grinover também ressalta que a atuação do desenhista industrial deveria pressupor seu envolvimento em todas as etapas do processo, "tanto nas origens, como no desenvolvimento, concretização, produção e circulação do produto" (Ibidem, p.52). Além disso, caberia a esse profissional uma importante função de mediação.

O desenhista industrial, quer como indivíduo isolado, quer como integrante de uma equipe, é um técnico de natureza toda especial, atua efetivamente como mediador entre a indústria e o mercado consumidor, entre as exigências da produção e as necessidades práticas e culturais do consumidor. (IBIDEM, p.52).

A questão da formação do gosto também não seria esquecida por Grinover, que reconheceria no desenho industrial a função de educação das massas: "hoje o objeto industrial é considerado como resposta às necessidades atuais e contemporâneas da funcionalidade e da economia, bem como àquelas do gosto e da cultura" (Ibidem, p.54).

E por fim, conclui com uma menção que alinhava as componentes técnicas e éticas que dão lastro à profissão:

o D.I. intervém diretamente no mundo da produção introduzindo a consciência segura de sua tarefa, fruto de uma posição correta e honesta, baseada no perfeito conhecimento da realidade e à luz dos valores éticos preconizados para a nossa civilização. (IBIDEM, p. 54)

$\mathrm{Na}$ edição seguinte, número 77, de maio/junho de 1964, Habitat dá continuidade à exposição de ideias sobre o desenho industrial publicando mais um 
artigo de um dos membros da diretoria da ABDI, o professor de Teoria da Informação da ESDI Décio Pignatari. O texto se inicia com alguns parágrafos anteriormente publicados no escrito de Grinover e em seguida faz um resumo histórico da atividade, mencionando alguns de seus principais personagens e instituições internacionais.

Mais adiante, entretanto, Pignatari introduz ideias atualizadas em relação ao desenho industrial e à sua pedagogia, como o operacionalismo científico de Tomás Maldonado e a crítica à boa forma de Rayner Banham, em favor de uma estética transitória para os produtos de consumo em massa. De acordo com Pignatari, a sociedade industrial nos anos 1960 cedia terreno à sociedade da informação, e o desenho industrial não poderia deixar de levar em conta essa importante mudança.

A máquina, em nosso século, principalmente a cadeia de montagem de Ford e, agora, com a produção automatizada, tem muito mais analogia com o sistema nervoso (comandos, mensagens, performances operacionais) do que com o sistema muscular, e maravilha nosso tempo, não tanto pela variedade como pela quantidade de seus produtos. Hoje, mais do que para o objeto, para a coisa, voltase para a relação entre as coisas, para a relação entre os objetos. Falar em relação, falar em sistema nervoso, é falar em linguagem. Entramos na era da linguagem, na era do código, na era dos signos. (PIGNATARI, 1964: 41)

Para ele, seria possível se pensar nesses termos tanto a realidade da prática profissional quanto do ensino da atividade. Em 1965, por exemplo, Pignatari proporia uma reformulação curricular na ESDI, alegando que se "o desenhista industrial estava voltado para a produção em série, sua formação não poderia continuar a ser artesanal" (BRAGA, 2011: 59-60), e nesse sentido, dentre outras mudanças, defenderia a introdução dos computadores no ensino do design. Outro interessante e inusitado ponto levantado por Pignatari - visto no conjunto dos artigos publicados por Habitat até então - é a ideia da antropofagia cultural, tão cara aos primeiros modernistas do país, como caminho na busca por um desenho industrial autenticamente brasileiro.

Foi o grande poeta Oswald de Andrade quem, há 35 anos, lançou a "antropofagia", como a filosofia e a sociologia - melhor ainda - como a antropologia cultural mais adequada à civilização brasileira, antropofagia que caracterizaria o pragmatismo brasileiro, um pragmatismo latino e nativo, mas não isolacionista, ao contrário: internacional, aberto para o mundo. Em defesa da criação de valores nacionais próprios de validade internacional, com gabarito de exportação, através de deglutição e assimilação do que é útil no produto estrangeiro (seja objeto, know-how ou outra informação) e devolução ao mercado mundial de produto nacional de qualidade, ou linguagem (diríamos) própria. (PIGNATARI, 1964: 42)

Em sua perspectiva, essa poderia ainda ser a chave para se estancar a ampla prática da cópia de artefatos industrializados de origem estrangeira - ou não - vigente no país.

[...] podemos afirmar que o desenhista industrial no Brasil já fará muito se começar por rejeitar e combater energicamente a cópia, o plágio, a imitação e a deturpação do produto estrangeiro. Como já dissemos, sua atitude deve ser crítica, antropofágica, a bem da profundidade de sua atuação. (Ibidem, p. 42) 
Segundo Pignatari, esta função crítica seria de competência específica do desenhista industrial. Ele deveria lutar por autonomia, visto que a sua atuação nos "departamentos de estilo" das indústrias era bastante limitada, já que eram desenhados ali apenas partes ou detalhes de um objeto, geralmente importado. Para romper com esse modelo, seria vital despertar a consciência do empresariado da necessidade de seus serviços em todas as etapas do projeto. Divulgar-se através de revistas especializadas era uma forma de trabalhar em favor dessa conscientização do desenho industrial, e nesse sentido Habitat demonstrou-se um parceiro solícito.

\section{CONCLUSÃO}

Reconhecida como uma das mais importantes revistas culturais com foco na arquitetura que já circularam no país, é impossível não constatar o envolvimento muitas vezes intenso de Habitat nas questões do desenho industrial ao longo de sua existência.

Como parte, em seus primeiros anos, do programa cultural encabeçado pelo MASP, a revista desde o início atuou no sentido de esclarecer a respeito do design como nova atividade projetual. Suas edições inaugurais preocuparam-se em definir o desenho industrial e em evidenciar a relevância do papel desse novo profissional na sociedade brasileira, que então preparava-se para experimentar um surto de industrialização no país.

O desenvolvimento da atividade no país seria acompanhado de perto por Habitat, principalmente no segmento da produção de mobiliário. A demanda por instituições de ensino especializadas na área ou questões centrais à ampliação do mercado de trabalho, como o problema das cópias e do pagamento de royalties por projetos importados, também tiveram espaço na revista. Em relação ao viés cultural, Habitat colocaria em evidência a tarefa do desenho industrial na disseminação do gosto moderno, dada sua capacidade, a princípio, de democratizar o acesso a bens de consumo de qualidade funcional e estética.

Dentre os tópicos centrais na cobertura da revista aparece ainda, no início da década de 1960, a institucionalização da atividade, especialmente a de natureza classista, através da publicação de artigos assinados pelos diretores da ABDI. Naquele instante, o ensino em nível superior especializado na área era uma realidade e escritórios e profissionais autônomos buscavam espaço no mercado de trabalho. Esses novos agentes continuariam a elaborar e divulgar na sociedade as ideias que davam fundamento à pratica e à pertinência do desenho industrial no Brasil e Habitat seria uma aliada nesses esforços até seu último número.

\section{REFERÊNCIAS}

BRAGA, Marcos. ABDI e APDINS-RJ: história das associações pioneiras de design do Brasil. São Paulo: Blucher Acadêmico, 2011.

CAUDURO, João. Origem e desenvolvimento do desenho industrial no Brasil. Habitat, São Paulo, n. 76. mar. abr. 1964.

FRANCO, Maria Laura. Análise de conteúdo. Brasília: Liber, 2005.

GRINOVER, Lucio. Desenho industrial. Habitat, São Paulo, n. 76. mar. abr. 1964. 
HABITAT, São Paulo, n.1. out. nov. dez. 1950.

São Paulo, n. 25. dez. 1955.

, n. 84, jul. ago. set. out. nov. dez. 1965.

LEITE, João. A herança do olhar: o design de Aloisio Magalhães. Rio de Janeiro: Artviva, 2003.

PIGNATARI, Décio. O desenhista industrial. Habitat, São Paulo, n. 77. mai. jun. 1964.

STOLARSKI, André. A identidade visual toma corpo. In: MELO, Chico Homem de. 0 design gráfico brasileiro: anos 60. São Paulo: Cosac Naify, 2008

STUCHI, Fabiana. Revista Habitat: um olhar moderno sobre os anos 50 em São Paulo. Dissertação de mestrado. Faculdade de Arquitetura e Urbanismo. Universidade de São Paulo. São Paulo, 2007.

WOLLNER, Alexandre. Alexandre Wollner: design visual 50 anos. São Paulo: Cosac Naify, 2003. 